\title{
Optimization of process parameters for pilot-scale liquid-state bioconversion of sewage sludge by mixed fungal inoculation
}

\begin{abstract}
Liquid-state bioconversion (LSB) technique has great potential for application in bioremediation of sewage sludge. The purpose of this study is to determine the optimum level of LSB process of sewage sludge treatment by mixed fungal (Aspergillus niger and Penicillium corylophilum) inoculation in a pilot-scale bioreactor. The optimization of process factors was investigated using response surface methodology based on Boxï Behnken design considering hydraulic retention time (HRT) and substrate influent concentration (S0) on nine responses for optimizing and fitted to the regression model. The optimum region was successfully depicted by optimized conditions, which was identified as the best fit for convenient multiple responses. The results from process verification were in close agreement with those obtained through predictions. Considering five runs of different conditions of HRT (low, medium and high 3.62, 6.13 and 8.27 days, respectively) with the range of S0 value (the highest 12.56 and the lowest $7.85 \mathrm{~g} \mathrm{Li}$ 1), it was monitored as the lower HRT was considered as the best option because it required minimum days of treatment than the others with influent concentration around $10 \mathrm{~g} \mathrm{Lī} 1$. Therefore, optimum process factors of 3.62 days for HRT and $10.12 \mathrm{gLi} 1$ for S0 were identified as the best fit for LSB process and its performance was deviated by less than $5 \%$ in most of the cases compared to the predicted values. The recorded optimized results address a dynamic development in commercial-scale biological treatment of wastewater for safe and environment-friendly disposal in near future.
\end{abstract}

Keyword: Bioconversion; Hydraulic retention time; Mixed fungal inoculation; Optimization; Sewage sludge 